\title{
Citizen Participation in the Public Policy Process in China: Based on Policy Network Theory
}

\author{
Nan Zhou ${ }^{1}$, Xiangze Xiao ${ }^{1,2}$ \& Feng Feng ${ }^{1}$ \\ ${ }^{1}$ School of Public Affairs, University of Science and Technology of China, Hefei, China \\ ${ }^{2}$ Institute of Management of Technology, National Chiao Tung University, Hsinchu, Taiwan \\ Correspondence: Nan Zhou, School of Public Affairs, University of Science and Technology of China, No. 96, \\ Jinzhai Road, Baohe District, Hefei, Anhui 230026, China. E-mail: munan11@mail.ustc.edu.cn
}

\author{
Received: September 17, 2014 Accepted: September 23, 2014 Online Published: October 20, 2014 \\ doi:10.5539/par.v3n2p91 \\ URL: http://dx.doi.org/10.5539/par.v3n2p91
}

\begin{abstract}
This article based on policy network theory analyzes the internal and external factors affecting citizen participation in the public policy process in the Chinese context. It displays that the policy network resources possessed by citizen are in a lower level and that their policy belief perform unreasonable or obscured, which belong to the internal factors. Besides, it also shows how the external factors, including policy network circumstance and policy network interactions among citizen and other network actors, influence citizen participation. In terms of these factors, the article provides some policies and suggestions about improving and motivating citizen participation for policy makers in taking account of how to reinforce the effect on citizen participation in the public policy process when making policies. Finally, we conclude that other network actors have not been researched deeply and further research should be laid in mass media, experts and scholars, grass-root NGO, etc.
\end{abstract}

Keywords: citizen participation, public policy process, policy network, network resources, policy belief, network interaction

\section{Introduction}

"Citizen participation" is a fundamental issue in the field of political philosophy (Webler \& Renn, 1995). The earliest description about citizen participation originated from Ecclesia of Athens. At that time, every Greek ancient city-state could be viewed as a city society which was composed of all the citizens and emphasized freedom, democracy and autonomy. At the age of Virginia and New England colonial settlements, decision-making power was seized in the hands of those free, White, property-owning, adult male and elite citizens (Roberts, 2004). With the time advanced and the history developed, the scope of citizen participation gradually expanded. The power and right possessed by citizen also became greater and greater.

Citizen participation mainly discusses the redistribution of citizen power, including how the information is shared; how goals and policies are made, how tax resources are distributed; how programs are operated and how interest relationships are configurated (Arnstein, 1969). As for the merits and demerits of citizen participation in government decision making, Irvin and Stansbury (2004) made a clear analysis about advantages and disadvantages to citizen participants and government from the aspects of decision process and outcomes. They argued that citizen participation could promote citizen participants to acquire related skills and some control over policy process, but it existed the problems of time consuming and detrimental outcomes if serious affected by some interest groups. Although citizen participation is not thought to be perfect both from the theory and the practice, it is not easy to avoid citizen participation in researching public policy process and government decision-making when democratic politics develop increasingly and citizen awareness improve gradually. Particularly under the background of advocating the new governance all around the world, this theory framework not only refer to political tools but also practice and process for citizen to participate in the work of government (Bingham, Nabatchi \& O'Leary, 2005).

Since the reform and opening policy of China started, Chinese leaders have been sticking to lay more emphasis on the significance of citizen participation orderly. The fifth Plenary Session of the 15th Central Committee of the Communist Party of China (short for CPC) in 2000 passed "Report on the Outline of the tenth five-year Plan 
for National Economic and Social Development", in which the concept of "citizen participation" was identified for the first time and the proposition about "expanding citizen participation orderly" was also put forward. Furthermore, Report on the17th National Congress of CPC in 2007 indicated that "we should persist in all the rights of the state belonging to the citizen" and that "we should expand the scope of citizen political participation orderly from all levels and all areas". After five years, Report on the18th National Congress of CPC pointed out "accelerating the promotion of the process of systematization, standardization, routinization about socialist democracy" and "expanding citizen political participation orderly from all levels and all areas".

According to the attitude toward citizen participation from the central government officials in China, it can be seen that they were endeavoring to enhance the status of citizen participation and construct the civil society. Besides, Chinese central government was exploring a harmonious relationship between governance and citizen participation (Enserink \& Koppenjan, 2007). However, what are the real conditions on citizen participation in the Chinese context? How can Chinese citizens participate in the public policy process? Which difficulties do they encounter? Which methods and approaches can they take advantage of? How do other participants (e.g., governments, media, experts) interact with citizens? Thus it is not difficult to find that citizen participation is a complex problem which involves in citizens and relations among citizens and other actors. Taking account of it, this paper attempts to research citizen participation in the Chinese context based on policy network theory.

In this paper, we first conducted a thorough literature review about Chinese citizen participation from the variety of public policy and public management journals in China. Then we give a brief introduction of policy network theory and explain the applicabilities for using this theory to research Chinese citizen participation. The paper analyzes the internal and external factors affecting citizen participation in public policy process respectively applying policy network theory in the subsequent section. The following section provides corresponding countermeasures and suggestions on the basis of analyzing results. Finally, we draw the conclusion.

\section{Citizen Participation Research in Chinese Academic Literature}

The research on Chinese citizen participation in Chinese academic literature can be classified as four groups in terms of different research perspectives.

1) About research on function, value, significance and approach of citizen participation. For examples, Bo (2000) summarized the foundation and systematic guarantee of public management which Chinese citizen could take part in and pointed out that citizen could achieve goals through selections, villager autonomy, democratic appraisal, etc. Wang (2005) researched the value of citizen participation in the public policy during transitional period from the viewpoint of interest analysis and held that some participation approaches should be established and enhanced, such as public hearing, mass observation, policy consult, etc. Fu \& Fu (2007) made a correlation analysis on information channels, motivations and frequencies of Chinese citizen participation in the policy setting based on social gender. Yin \& Shang (2009) argued how the organizations of letters and visits in China implement their duties and reform the structures. Chu (2009) researched the institutional framework of citizen participation and pointed out that a lack of procedure and technology could not meet their systematic needs.

2) About research on concrete cases of citizen participation. Zhu (2007) researched how the citizens in Zeguo of Wenling City in Zhe Jiang Province joined in the public infrastructure project involved in people's livelihood for providing a kind of model which was worth of learning to the development of basic level democratic politics of other places. Wang (2011) regarding the open government decision making in Hangzhou City as a study object, analyzed the participating approaches about the government policy making and the management practice from the government on the grounds of the angle of citizen participation. Chen (2012) argued how to maintain a balanced and healthy relationship among government leading, limited market and citizen participation by analyzing a case of public bikes service in Hangzhou City.

3) About research on citizen participation using the Internet. For instances, Zheng \& Xue (2009), on the basis of the theory of deliberative democracy originated from Habermas, discussed the mechanism of public opinion formation on the Internet and its approach to influence the policy-making. Wei \& Yuan (2009) explored the Internet participating situation and its constitution through investigating the status quo concerning Chinese citizen participation empirically. Qi \& Wang (2010) considered citizens' network participation could elevate or lower the credibility of public policy, and related measures on how to combat imperfections caused by network participation were put forward.

4) About research on dilemma of citizen participation. Sun (2006) asserted that there were ten dilemmas in Chinese citizen participation, including vague cognition, low participation ability, conflict between public interest and private interest, etc. Luo (2008) identified many dilemmas existed in the process of citizen participation ranging from political apathy to character, efficiency, quality paradox. Liang (2009) discussed four 
dilemmas of citizen participation in public policy making, which are subject dilemma, channel dilemma, information dilemma and organization dilemma. Zang \& Wang (2012) explored problems on citizen participation in public policy process (e.g., weak participation awareness, opaque government decision, single participation approach and mechanism) and raised related solutions.

After reviewing and combing related literature, we can conclude at least four points. Firstly, Citizen participation can not only insure the intrinsic value of public interest, but also improve the quality of public policy and compensate drawbacks of the policy regulation so as to help government policy makers to make scientific and democratic decisions. Secondly, some cases on Chinese citizen participation demonstrate that citizens can affect public policy and government decision-making through various participation approaches. Thirdly, with the rapid development of the Internet technology, more and more citizens resort to the Internet to participate in public policy process. Compared to institutional participation channels, this kind of non-institutionalized approach using network can perform much more effective and efficient. Fourthly, although Chinese citizen participation develop toward a positive and progressive direction, citizens are still confronted with a number of problems and difficulties in participating the real public policy and public life.

From literature with regard to predicaments of Chinese citizen participation, it is not difficult to find that they all involved in citizen qualification or character to carry out the research. And these researches were far from comprehensive. Furthermore, in the public policy process there are other participants besides citizen, so we need to consider them when researching citizen participation. Nevertheless, we seldom find literature exploring interactive relationship among citizen and other participants. In order to shrink the gaps mentioned above, the paper attempts to use policy network theory to research Chinese citizen participation in the process of public policy with a dynamic and comprehensive perspective. We hope this research can provide a kind of new study way for citizen participating in public policy process in the Chinese context. Meanwhile, we also hope that it can afford scientific and reasonable theoretical evidence for establishing civil society and pushing social governance philosophy.

\section{Policy Network Theory and its Application Analysis}

\subsection{The Overview of Policy Network Theory}

Policy Network, dating back to the United States between 1950-1960 and developing in Britain, is prevalent in the whole western academic circle. It can be viewed as an analytic approach, which introduces network theory into policy science. It is thought that this approach can replace policy analysis, new public management as well as new institutionalism (Dye, 1992). Generally, policy network includes two theoretical origins: one is the theory of social organization in the 1950s; another is the doctrine about power discussion of political field (Klijn \& Koppenjan, 2000).

Policy network has experienced a gradual development process almost half a century and has formed three research levels. Firstly, micro-level research represented by American scholars who emphasized personal relationship and interaction among different actors in the network. They focused on "iron triangles" of America and on issue network containing subgovernments and subsystems (Gais, Peterson, \& Walker, 1984). Secondly, meso-level research on behalf of the ideas from British experts who regarded policy network as "interest intermediation structure" based on previous research. They analyzed the relationship between interest groups and governments in order to promote and enrich the development of policy network theory (Rhodes, 1990). Since American and British scholars aimed at exploring the interest relationship among network actors, they were viewed as "interest mediation structure". Thirdly, macro-level research represented by German and Dutch scholars. German experts claimed that policy network was a kind of new governance mode defined in the midst of market and government, which was characterized by informal dominance, decentralization and parallel relation (Kenis \& Schneider, 1991). Scholars from Holland mainly researched network governance. They pointed out that policy network constituted a steady pattern of social relationship gathered interdependent actors (Kickert, Klijn \& Koppenjan, 1997). It was clear that scholars from Germany and Holland defined policy network as a governance mode with a network perspective. As a result, they belonged to another school: Governance School.

The term policy network are defined as "a cluster of actors or organizations who connect with each other due to resource dependence through collective action" (Rhodes, 1997). Based on Marsh and Rhodes' typology, policy network are classified into five types in terms of the number of participants, the frequency of interaction, continuity, degree of consensus, the nature of relationship, distribution of resources and the balance of power: policy community; professional network; intergovernmental network; producer network and issue network (Marsh \& Rhodes, 1992), as indicated in Table 1. Moreover, policy network resources can also be classified into 
five kinds: authority, finance, legitimacy, information and organization (Marsh \& Rhodes, 1992).

Table 1. Types and characteristics of policy network

\begin{tabular}{cl}
\hline Types & \multicolumn{1}{c}{ Characteristics } \\
\hline Policy community & $\begin{array}{l}\text { Stable and high limited members; hierarchical interdependence; limited parallel } \\
\text { connection }\end{array}$ \\
& $\begin{array}{l}\text { Stable and high limited members; hierarchical interdependence; limited parallel } \\
\text { connection; serving for professional interest }\end{array}$ \\
Professional network & Limited members; limited hierarchical interdependence; extensive parallel \\
Intergovernmental & connection \\
network & Uncertain members; limited hierarchical interdependence; serving for producers' \\
Producer network & interest \\
Issue network & Numerous and unstable members; limited hierarchical interdependence
\end{tabular}

Source: Marsh D and Rhodes R A W Policy Networks in British Government. Clarendon Press, 1992.

According to Table 1, it is not difficult to find that these five types of policy network present a spectrum ranging from a highly integrated policy community to a loosely integrated issue network continuum (Rhodes, 1992; Koranteng \& Larbi, 2008). Policy community features a very limited participants whose relationships are stable, high continuity and consensus, interdependence due to sharing resources and balanced power, while issue network is characterized as a large number of participants whose contacts fluctuate, unstable continuity and consensus, restricted resources and unequal power (see Table 2).

Table 2. Characteristics of policy community and issue network

\begin{tabular}{lll}
\hline \multicolumn{1}{c}{ Dimension } & \multicolumn{1}{c}{ Policy community } & \multicolumn{1}{c}{ Issue network } \\
\hline Membership & Very limited number, some groups consciously & Large \\
$\begin{array}{l}\text { (1) Number of } \\
\text { participants }\end{array}$ & excluded & $\begin{array}{l}\text { Encompasses range of affected } \\
\text { interests }\end{array}$ \\
(2) Type of interest & Economic and/or professional interest dominates \\
\hline
\end{tabular}

\section{Integration}

(1) Frequency of interaction

(2) Continuity

(3) Consensus
Frequent, high-quality, interaction of all groups on all matters related to policy issues

Membership, values and outcomes persistent over time

All participants share basic values and accept the legitimacy of the outcome
Contacts fluctuate in frequency and intensity

Access fluctuates significantly

Some agreement exists, but conflict is ever present

\section{Resources}

(1) Distribution of resources (in networks)

(2) Internal distribution

Power
All participants have resources, relationship is one of exchange

Hierarchical; leaders can deliver members
Some participants have resources, but they are limited

Varied and variable distribution and capacity to regulate members

Unequal powers, reflecting unequal resources and unequal access-zero-sum game

Source: Marsh D and Rhodes R A W Policy Networks in British Government. Clarendon Press, 1992. 


\subsection{The Applicability Analysis of Policy Network}

For policy network theory originated from western countries as mentioned above, experts and scholars have carried out extensive and deep researches on whether this theory was applied in the context of China. These researches mainly focused on the countryside reform of tax and fee (Tang, 2006), medical treatment (Zheng, De \& Koppenjan, 2010), education and housing (Deng, 2011), etc. The research results demonstrated that policy network theory could apply to China in general, especially in analyzing intricate problems in diverse society and diverse social actors participating in the public policy and public affairs. It has shown strong vitality and powerful explanation. Consequently, we assert that policy network theory is applicable to study Chinese citizen participation in the public policy process as well. The concrete reasons are as follows:

Firstly, the formation of social diverse interest subjects requires using policy network theory to analyze citizen participation in the public policy process. With the rapid development of economy and technology, interest subjects in Chinese society tend to develop diversely, and their interest demands also become much more various. All kinds of interest subjects begin to form complicated relationship of resource interdependence. In order to fulfill their respective interest targets, citizen, as one of the interest subjects, need to exchange their resources with others, such as governments, interest groups, mass media, when participating in the public policy. Policy network theory exactly came into being under the background of more and more complex social problems and diverse interest subjects development. Multiple actors in the policy network interact with each other for attaining predicted goals through exchanging resources.

Secondly, the conflict and contradiction of interest relationships require using policy network theory to analyze citizen participation in the public policy process. As diverse subjects' interest structure has been identified and their interest demands take on disparities, it is quite easy to generate interest conflicts and interest contradictions. In the policy network, both strong interest subjects (e.g., governments and interest groups) and weak interest subjects (e.g., grass-root NGO and citizen) can affect policy making and policy implement through frequent interest interactions. Besides, successful policies owe to the outcomes of interest bargaining among all kinds of interest subjects. These conform to the core ideology of "Interest Intermediation School", which explores interest interactions among interest subjects involved in the policy network.

Thirdly, the growing up of governance theory and the rising of civil society require using policy network theory to analyze citizen participation in the public policy process. After experiencing market failure and government failure, Chinese governments at all levels have drawn on the advantages of network governance raised by "Governance School". This mode argues that governments should not play a leading actor in the policy process, but becoming one of the participants who interact with other actors. And the government officers are permitted to mobilize all the resources distributed in public organizations and private sectors. This public governance idea not only provide a necessary theoretical foundation for the transition of government function from management to service, but also create a kind of sound systematic environment for establishing civil society in China.

\section{Factors Affecting Chinese Citizen Participation in the Public Policy Process}

Although the significance and influence with regard to citizen participation have been fully admitted, Chinese citizens' status in joining public policy process is becoming increasingly marginalization. Their voices are so trivial that it is hard for government decision makers to listen and accept. In theory, citizens would take part in the process of public policy together with Central People's Government (short for CPG), Local Governments (short for LG), representatives of National People's Congress (short for NPC) and Local People's Congress (short for LPC), members of Chinese People's Political Consultative Conference (short for CPPCC) and Local People's Political Consultative Conference (short for LPPCC), interest groups, experts, media and grass-root NGO. However, in reality, Chinese citizens are forced to descend to network peripherality for being affected by the internal and external factors.

\subsection{Analysis of Internal Factors}

On the grounds of policy network theory, there are two primary internal factors influencing citizen participation, which are network resource occupation and policy belief respectively. Network resource occupation can be viewed as a crucial factor.

\subsubsection{Network Resource Occupation}

As mentioned before, policy network resources can be classified into authority, finance, legitimacy, information and organization. Network actors occupy network resources in varying degrees because of their different qualifications and network status. Specifically, actors possessing strong authority, abundant finance and comprehensive information can be usually in a core position. They can easily exchange resources with other 
actors. Nevertheless, those who have less resources are more likely to suffer isolation and repulsion. They often locate in the peripheral network position. If the degree of network resources possessed by citizen could be measured with high level, middle level and low level, citizens' relative condition of resource occupation is as follows (see Table 3).

Table 3. Network resource occupation of Chinese citizen

\begin{tabular}{cccccc} 
Resources & Authority & Finance & Legitimacy & Information & Organization \\
\hline Migh & $\mathrm{N}$ & $\mathrm{N}$ & $\mathrm{Y}$ & $\mathrm{N}$ & $\mathrm{N}$ \\
Low & $\mathrm{N}$ & $\mathrm{N}$ & $\mathrm{N}$ & $\mathrm{Y}$ & $\mathrm{Y}$ \\
\hline
\end{tabular}

Note. $\mathrm{N}=\mathrm{No} ; \mathrm{Y}=$ Yes.

1) Authority and finance. Compared to other network resources, authority and finance are the most important, which decide network actors' status and influence. Governments (especially the central governments) play a core role in the process of public policy as they possess strong authority. Some powerful interest groups, due to their abundant finance resource, also influence the policy trend to a large extent. However, Chinese citizens possess these two resources in a very low degree, so they are confronted with an adverse situation when interacting with other actors.

2) Information. Citizens in China occupy information in a middle level. Though "Government Information Publicity Regulations of People's Republic of China" has been implemented for over five years, there still exists behaviors about intruding on citizens' justified right to know, disclosing information selectively, and etc. For example, Zhu (2011) presented that the residents in Nujiang prefecture are those who had the least information and the expression channels compared to other network subjects when participating the project of the hydroelectric exploration of Nujiang utilizing policy network theory.

3) Organization. Increasing research evidences have proved Chinese citizens participating in the public policy in the form of organization developed not mature. In recent years, Chinese governments have made great efforts to encourage and support the development of grass-root NGO and autonomous organization of a mass. Additionally, they have tried to advocate citizens to participate in the policy making actively. However, as citizens are not fully aware of the significance of organization participation and they are not good at uniting with those who have the same interests and demands, it is hard to achieve goals and ensure their rights as a result of lacking necessary regulations and expression channels.

4) Legitimacy. Legitimacy belongs to a kind of fundamental resource. Authority, finance, information and organization would manifest their respective functions and values on the premise of having legitimacy. Based on Chinese citizens' political rights endowed by the constitution, it is thought that they are equipped with higher legitimacy in the process of public policy. But noteworthy is the fact that legitimacy must combine with other four resources in the real participation process when evaluating its effect. That is to say, we should estimate participation level through the entire network resource occupation condition.

Overall, from the aspect of the policy network resources, the participation legitimacy of Chinese citizens show a high level, but the authority and finance display a lower level. The information and organization occupied by citizens are in a middle level. Thus, compared to other network actors, citizens' resource occupation is relatively insufficient and they are more likely to be marginalized.

\subsubsection{The Policy Belief}

The concept of Policy Belief derived from the Advocacy Coalition Framework established by Paul Sabatier (Sabatier, 1988). This framework based on policy network theory and claimed that all the actors took concerted actions in the public policy process when they possessed the same policy belief and supported the same policy.

The policy belief of citizens can be expressed a fundamental cognition and a value preference as for the public problem (before entering the policy agenda) or the policy problem (after entering the policy agenda). Policy belief can affect the behavior of citizen participation. Citizens with the same policy belief are much easier to 
form an alliance or an organization. Furthermore, citizens' policy belief have a positive correlation with the attention citizens pay to a certain public problem or policy problem. If citizens pay more attention to a problem or an event, their policy belief become much stronger; if citizens pay little attention to a problem or an event, their policy belief display much weaker. At present, Chinese citizens usually lack rationality and carry with high utility purpose in participating the policy process. Most citizens lack necessary policy belief in protecting public interest and showing citizen obligations, while they lay more emphasis on the problems which have direct or indirect relations to them and keep higher policy belief for these problems. In addition, there still exists some citizens whose policy belief are ambiguous. In other words, they do not have clear attitudes and preferences. Their participation can be viewed as a kind of herd behaviour, which tend to be a performance of lacking policy belief.

\subsection{Analysis of External Factors}

From the perspective of policy network, there are two external factors influencing citizen participation in the process of public policy. One is the environment of policy network; the other is the interactions among citizen and other network actors.

\subsubsection{The Environment of Policy Network}

The environment of policy network, to some extent, can affect the network actors' attitudes and behaviors. Considering the network classification and their traits indicated in Table 1 and Table 2, a figure can be drawn, which aims at describing all the network actors participating in the public policy process in different kinds of networks (see Fig. 1). Each network represents a network environment.

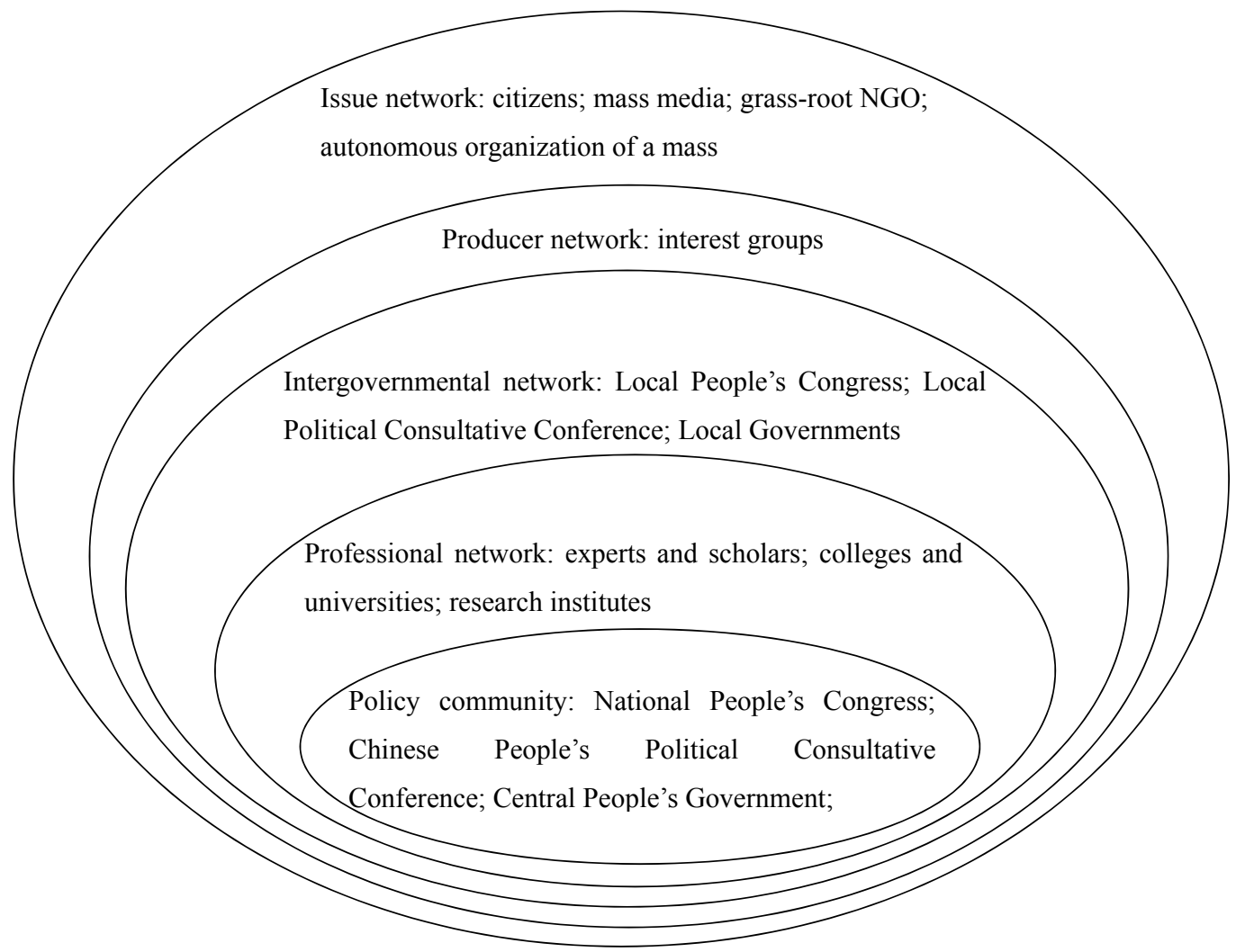

Figure 1. Actors in different networks in the Chinese context

From Fig.1, it can be seen that every network includes one or more actor(s) whose policy belief and behaviors are affected by the network environment. (1) National People's Congress (as the highest state power organ in China) and the Central People's Government (as the highest state administration organ in China) are in the key situation in the process of policy making, so they should belong to policy community; Chinese People's Political Consultative Conference can represent citizens to exercise three functions: political consultation, democratic supervision and participation in the administration and state affairs discussion. Although it does not possess the state power directly, it is entrusted political power and social compelling power by the constitution. 
Consequently, it should also be included in the policy community. (2) Professional network serving for professional interests refers to the networks which are made up of individuals in specific fields or organizations engaged in professional jobs, containing experts and scholars, colleges and universities, research institutes. (3) Governments at all levels need to interact with each other, which constitute the overriding contents of intergovernmental network. In China, the central government vertically leads the local governments. Since the central government belongs to the policy network, we can classify the local governments into the intergovernmental network. Similarly, Local People's Congress and Local Political Consultative Conference can be grouped into the intergovernmental network. (4) Producer network serving for producers' interests is mainly made up of interest groups. Compared to the "iron triangles" in America, Chinese interest groups do not develop maturely enough. They can not control party election and political changes. Therefore, interest groups in China should belong to producer network rather than policy community. (5) Issue network locates in the outermost layer of the policy network due to the loose structure, numerous members, low degree's system and the informal decision-making way. Members in issue network lack imperative network resources. They always play a peripheral role in taking part in the public policy and it is difficult form them to interact with other actors effectively. This network includes citizens, mass media, grass-root NGO and autonomous organization of a mass.

4.2.2 The Interactions among Citizens and Other Actors

On the basis of policy network, a figure concerning the interactive relationships of all the actors in respective networks can be drawn (see Fig. 2). From the figure it is found that the actors in the policy network are numerous and that their interactions display complicated. In the public policy process, Chinese citizens can not only interplay with other actors in its own network, but can interact with actors from other networks. However, citizens can not fully exchange resources with every actor in reality. For the Central Government in the policy community locates in a core position, citizens in the marginal network are too difficult to connect with it. Interest groups in the producer network, especially the powerful interest groups with monopoly status, mainly interact with governments (including the Central Government and the Local Governments) so as to make a great influence on the policy making and they usually ignore the interest demands of citizens. Colleges, universities and research institutions in the professional network participate in the process of public policy in the form of organization basically. They can provide professional knowledge and technology support for decision makers and they seldom connect with citizens directly. Given these actual conditions, the paper selects five typical interactive relationships to study: citizens and the Local Governments; citizens and NPC/CPPCC (LPC/LPPCC); citizens and experts/scholars; citizens and mass media; citizens and grass-root NGO. 


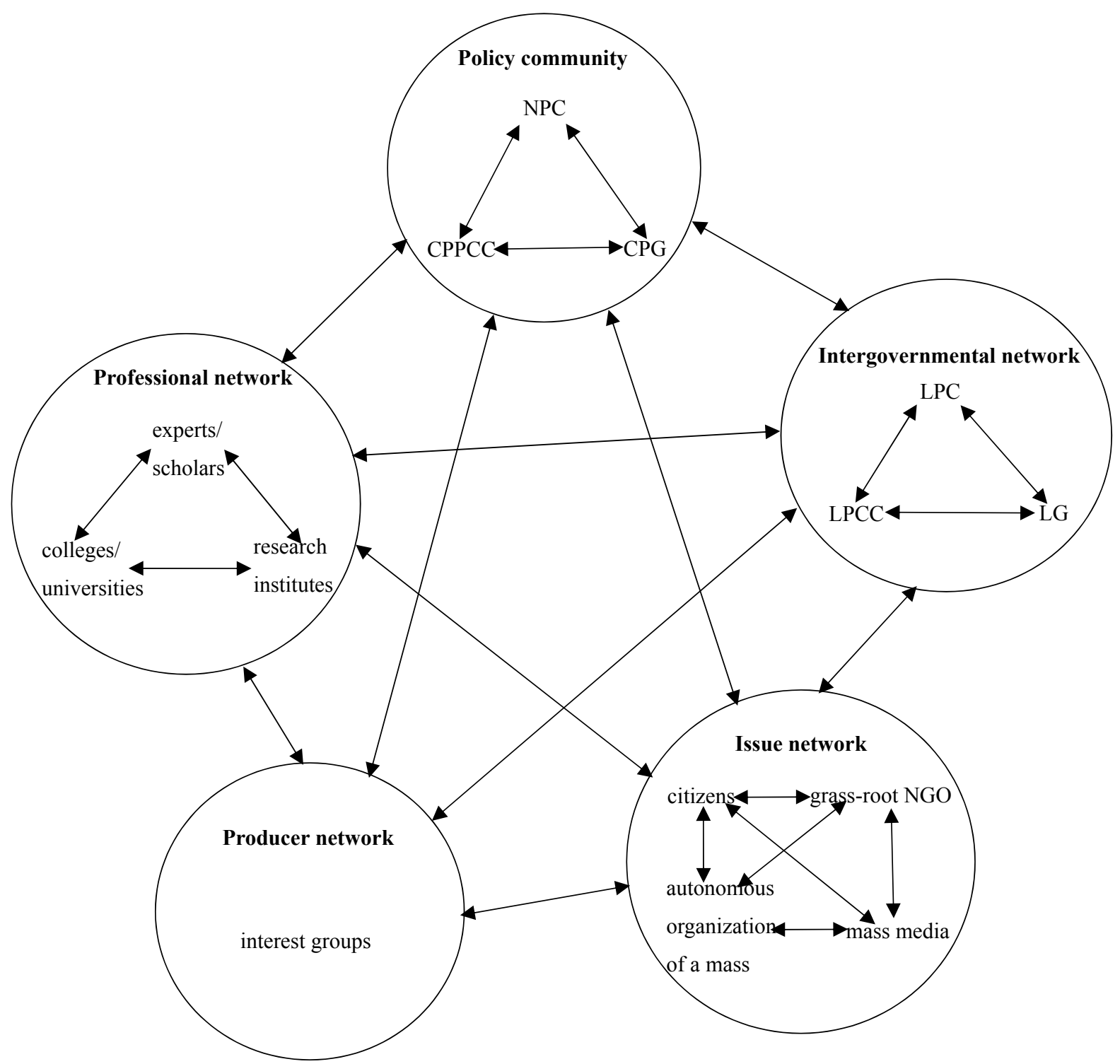

Figure 2. Interactive relationships of policy network actors in China

1) Citizens and the Local Governments. The local governments are the local highest administration organizations and possess rich network resources, so they are core actors in the intergovernmental network. Compared to the central government, the local governments are more likely to interact with citizens because they have a close connection to citizens. Since Chinese citizens locate in the marginalized network, they are in a weak position in the interaction with the local governments. Some local governments and the officials with narrow visions partially emphasize Gross Domestic Product (short for GDP). For developing the local economy, they even sacrifice the justified rights and interests of citizens, take strict measures to control and supervise their behaviors of upholding and protecting rights or suppress citizens by utilizing autocratic tools. For example, in Nov. 2012, landless farmers from Yiliang County in Kunming City, Yunnan Province knelt to visit Premier Wen Jiabao to reflect land acquisition. But unfortunately these residents were arrested by the local government officials and were made a penalty of administrative detention for seven days as they disturbed and hampered the public order. In addition, other local governments nominally provide systematic guarantees for citizen participation in the public policy process, but it just indicates a kind of formalism in essence. For instances, in some places in China, such as Harbin, Yinchuan and Jinan, held hearing meetings about the water price problem in 2009. In the meetings, residents' suggestions and thoughts were "over-represented" by the local government officials. As a result, hearing meetings were replaced by the price increasing meetings. Before the eighteenth NPC, Zhang Yaodong, a petitioner from Henan Province, encountered tragedy on the way of being repatriated to his home 
when he went to Beijing to appeal to higher authorities for help. These local governments would have been the systematic channels used for citizen participation, but their functions were distorted in the real implementation, gradually degenerating arenas which impeded citizens' demands and neglected their voices.

2) Citizens and NPC/CPPCC (LPC/LPPCC). Apart from the hearing system and the letters and visits system, the systems of NPC/CPPCC (LPC/LPPCC) are both Chinese citizens' systematic expression approaches. The interactive relationships between citizens and NPC/CPPCC (LPC/LPPCC) indicate the representatives from these organizations can visit citizens, listen to their voices, collect and write down important information conveyed by them. Then these representatives intensively reflect the information to NPC/CPPCC (LPC/LPPCC) held each year. In NPC/CPPCC in 2012, a representative of NPC called Huang Xihua advised that governments should bring the overtime pay to the range of exemption from personal income tax; Shu Anna, a representative of CPPCC, advocated that the policy of canceling teaching centers and merging primary and middle schools in rural areas should listen to the citizens' opinions. Moreover, in LPC/LPPCC in 2012, a representative of LPC from Hebei Province named Huang Qiuyun suggested regulating small vendors and individual workshops in the food industry according to legislations; Sun Lei, a representative of LPPCC from Shanxi Province called for strengthening the educational and managemental work concerning children who were left behind in rural areas. Thus it can be seen whether citizens can keep a harmonious relationship with NPC/CPPCC (LPC/LPPCC) depends on whether representatives or members from these institutions can go deep into citizens and stand for them to reflect problems effectively. Some representatives are busy with their enterprises and have no time to visit and investigate citizens' life, so their interest demands can not immediately deliver to decision-makers. Additionally, some other representatives submit their proposals that are not paid attention by the government officials, which means that these proposals never enter government agenda. Finally, it can impair the interaction effects between citizens and NPC/CPPCC (LPC/LPPCC).

3) Citizens and Experts/Scholars. Experts and scholars in the professional network play a role of "brain trust" and "think tank" in participating in the public policy. They can not only help decision-makers to make policy and estimate policy effect, but also facilitate the implementation of public policy. In practice, citizens seldom seek for experts' instruct and help. Experts and scholars can actively find out problems and reflect them to decision-makers on behalf of citizens. For examples, the case of Chen Chao's reeducation through labor occurred in Sep. 2007 and triggered 69 experts to make proposals to NPC, asking for launching the procedures of constitutional review about the reeducation-through-labor system. In Aug. 2012, a guidance document with regard to children of floating population attending college entrance examination not in the place of registration was introduced under the promotion of four ministries and commissions. After two months, there were almost 30 experts and scholars putting forward suggestions and solutions to the State Council, including examining qualifications of these children and their parents and identifying the deadline of this policy, etc. In the matter of fact, the interactive effects between citizens and experts/scholars rely on whether the latter can keep independent and objective attitudes when expressing their opinions. Experts' political independence, to a large extent, can affect the objectivity and justification of a certain policy. At present, there still exists some experts who lack political independence in China. They can not interact with citizens from the view of citizens' rights and interests, but only focusing on the preferences of government officials. Moreover, the solutions and approaches raised by the experts sometimes display "policy demonstration" trait to cater for some political officials. In the public policy process of "grass-roots units' supervision" in A Town in Shanghai, experts and scholars surveyed and demonstrated problems in the framework of decision-makers' instructions and orders, which hindered the progress of public policy towards scientization and democratization (Rong, 2012).

4) Citizens and Mass Media. Media, as "the fourth power" besides legislation, administration and judiciary, is not a tool which easily transmits information to the outside any more. It also strives to construct a communication platform between citizens and governments. It is noticeable that news media in China is supervised and managed by related government sectors, but some traditional mainstream media still give a priority to persist revealing the truth and defending citizens' rights. Taking mine disaster of Nandan County in Guangxi Zhuang Autonomous Region for an example, it was a first case that Chinese news media independently reported this accident, not only disclosing the lowdown, but also promoting legislative progress of "Production Safety Law of the People's Republic of China". As another example, food safety problems, such as tony red incident, baby milk powder accident, toxic capsules and so forth, were all disclosed by Chinese news media. Among them, baby milk powder accident exposed by media accelerated the end of national exemption system on food and facilitated the introduction of "Food Safety Law of the People's Republic of China". However, we need to understand that not all the media can perform independently and that there still exist those serving as government mouthpiece. These media produced false news, cheated and misled citizens out of a certain political need or officials' instigation. 
They can also take specific measures to shape public opinions which are beneficial to the governments regardless of trampling citizens' interest.

Besides from traditional media, the Internet, as a form of new media, can also be used by citizens to join in the policy process. Not only do they express interest demands and reflect realistic issues through the government websites, network forum and microblogs, but they can form supervision with the help of public opinions to prevent government officials from abusing power to seek personal gains or corrupting by taking advantage of Internet. For instance, on $11^{\text {th }}$ and $12^{\text {th }}$ Sep. 2009, a citizen called Zhang Jun from Shanghai posted messages on Aika Forum and Tianya Forum respectively to reveal Traffic Administrative Law Enforcement Battalion who collected evidence illegally with entrapment method, which caused a heated discussion from a wide range of netizens. After only half a month, the number of visits about all the messages was beyond 180,000. For another example, on $30^{\text {th }}$ Oct. 2012, a rural teacher from Hunan Province exposed that the primary school she worked did not reasonably use the state subsidies which were spent on improving students' dietary condition through writing Tweet. This piece of Tweet was acquired strong attention by a great number of netizens and caused related school leaders to be dismissed. In addition, since Chinese citizens gradually have higher enthusiasm for exercising supervision power and impeach power, anti-corruption with the Internet increasingly becomes a powerful weapon to disclose corrupt officials. Nevertheless, participation through the Internet can breed many problems due to its virtuality and randomness. Some citizens exaggerate the reality on purpose on the Internet, producing false information and defaming others. These detrimental behaviors need government regulate immediately.

5) Citizens and Grass-root NGO. Grass-root NGO is a kind of non-profit and non-political public service organization. As the organization structure is relatively loose, the members are usually characterized by plebification and popularization. Their network resources are not sufficient. Therefore, grass-root NGO and citizens, in essence, have a natural contact and both of them are in the issue network. Different from citizens, grass-root NGO has strong cohesion and development potential and their members can be engaged in public services and commonweal undertakings by utilizing social power generated from organizations. It can be viewed as a beneficial complement to governments. In China, grass-root NGO can independently represent citizens to put forward policy proposals to the governments when participating in the public policy process. There are some famous NGO, such as "Friends of Nature", "Amity Foundation", "Migrant Women' s Club", etc. However, distinct from western countries, citizens and grass-root NGO do not interact with each other frequently. On the one hand, Chinese citizens are not aware of the significance of participating in NGO; on the other hand, grass-root NGO develops not quite well and exists various problems, such as low level legitimacy, insufficient finance, short of specialized talents.

\section{Countermeasures and Suggestions on Problems of Chinese Citizen Participation}

Based on the perspective of policy network, we analyze the internal and external factors affecting Chinese citizen participation in the public policy process, and find that citizens in China are forced to network margin. In order to improve their weak position, some countermeasures and suggestions are raised.

\subsection{Enrich Citizens' Policy Network Resources}

As mentioned before, authority and finance occupied by Chinese citizens display a lower degree. The legitimacy possessed keeps a high degree, but it only rests on legal level. Citizens' occupation of information and organization are in a middle level. It is obvious that the conditions of authority and finance can not be enhanced in a short time, but the conditions of information and organization might be improved when taking some effective measures. As a consequence, we must combat two problems currently: one is how to ensure citizens to acquire timely, comprehensive and accurate information; the other is how to increase their organizational degree.

The right to know is a basic precondition of exercising other democratic rights. Ensuring citizens' right to know is a legal obligation of governments at all levels. To make citizen participation in the policy process effectively, governments must provide timely, accurate and relative comprehensive information. Firstly, government officials need to elevate the awareness of information disclosure. Secondly, governments need to implement "Government Information Publicity Regulations of People's Republic of China" strictly. Thirdly, the law system about government information publicity should be made a further improvement so as to identify the boundary between publicity and privacy. Fourthly, we should establish the judicial remedy system of government information publicity. Finally, governments at all levels in China need to strengthen the information system construction and update government information in time.

In participating in the process of public policy, organization participation are more effective than individual participation. Consequently, Chinese citizens should increase organizational degree of their own. Firstly, 
governments at all levels should encourage citizens, particularly those possessing the same interest demands and value preferences, to form organizations reasonably and legally and to participate in the public policy process through collective force to accelerate the establishment of policy agenda. Secondly, citizens in China also attempt to reflect real problems and raise suggestions to government sectors by taking part in corresponding NGO and autonomous organization of a mass.

\subsection{Strengthening Citizens' Policy Belief}

Aiming at the problems existed in Chinese citizens' policy belief, three suggestions are put forward.

Firstly, fostering citizen awareness and citizen spirit. Citizen awareness and citizen spirit are the necessary products of democratic politics development. A key step of strengthening citizens' policy belief is fostering citizen awareness and citizen spirit. Citizens in China must realize that they participate in the process of public policy not only for the purpose of satisfying and fulfilling their own demands, but also maintaining and guaranteeing public interests and public values. Governments should weaken citizens' "utility" policy belief while increasing their "public" policy belief for making a solid thought foundation for constructing civil society in China thoroughly.

Secondly, responding citizens' policy belief in time. Strengthening citizens' policy belief need governments feedback immediately. When citizens keep policy belief a high level to a certain problem, governments at all levels need to respond them rapidly to prevent citizens' policy belief from intensifying extremely. Otherwise, citizens can take destructive behaviors as punishments to governments' indifference, such as bypassing the direct leadership and presenting their appeals, mass disturbance, etc. Therefore, government officials must connect with citizens closely, master information conveyed by spread carriers correctly, and encourage citizens to express their ideas and thoughts actively.

Thirdly, building a harmonious and people-oriented atmosphere. Citizens' policy belief can be easily affected in a negative way because they always locate in the issue network. They either choose herd behaviors to participate in the public policy or never putting into practice. Thus, government officials should establish "people-oriented" governing philosophy and build a harmonious atmosphere to provide convenience for citizen participation, which make citizens in the network margin feel the meanings and values of participation. Governments also learn to shorten distance from citizens and improve their participation motivation.

\subsection{Constructing Positive Interactive Relationship between Local Governments and Citizens}

Political science theory emphasizes that government legitimacy is endowed by citizens, so governments at all levels have obligations to respond interest demands from citizens actively and to protect their political rights all the time. In the process of participation in the public policy, local governments should establish a kind of positive interactive relationship with citizens. At first, we should improve government officials' political thought level of "governing for the people" and transfer their functions (from management to service). Next, government officials should make related policies and regulations aiming to supervise and govern those who neglect citizens' voices and create a harmonious atmosphere for citizens' participation in China. Thirdly, local government officials should go deep into citizens to avoid their words and actions falling into formalism.

To build a positive relationship with citizens, People's Government in Sichuan Province stipulated some approaches in the document of "Promote Law-Based Administration Arrangements in 2013":

1) Implementing decision-making investigation system for demonstrating citizens' participation;

2) Carrying out decision-making draft consultation system;

3) Setting up decision-making participation system.

It was a first case that Chinese local governments pushed "open decisions" with the aim of encouraging citizens' participation. It was taken as a model learned by other areas.

\subsection{Perfecting Citizens' Institutional Expression Channels}

Because it is high-cost and inefficient for citizen participation through institutional channels, more and more citizens are unwilling to resort to this way and they would like to seek for non-institutionalized channels to express their interest demands. This trend tends to trigger citizens' institutional expressing function shrinking and even to distort the original intention of establishing these institutions. To improve the efficiency of citizen participation through institutional approaches, some measures should be taken to achieve a balanced development between institutional participation and non-institutionalized participation.

Firstly, making a further enhancement of people's congress system and political consultation system. A key point 
of enhancing these two systems is strengthening the interaction among deputies to the NPC/LPC, members of CPPCC/LPPCC and citizens and impelling these representatives to visit citizens frequently. It not only needs to set corresponding laws and regulations, such as "Deputies to NPC/LPC in Close Contact with Citizens Law", "Members of CPPCC/LPPCC Representing the Constituency Members Law", to ensure them perform correct functions. Furthermore, we also need to reinforce democratic supervision mechanism with regard to citizens towards deputies to the NPC/LPC and CPPCC/LPPCC members. And government decision-makers should pay more attention to the proposals raised by deputies and members. For proposals that need to be addressed immediately, government officials should bring them into governmental agenda in time to guarantee their interaction effectively.

Secondly, making a further improvement of public hearing system. In other words, Strengthening the scientific, normalized and programmed construction of public hearing system and providing a more expansive systematic platform for citizen participation. It requires governments to expand citizens' participation scope and to strengthen decision-making sectors' reflections from citizens' opinions in the hearing meetings. For realizing them, the most important thing is that the public hearing system must be identified in law forms. Specifically, through making "Public Hearing Law", we can identify applicable objects, procedures in public hearing meetings as well as legal validity of the results, especially making explanations about hearing materials and discussion programs published in public in advance to avoid information asymmetry.

Thirdly, making a further promotion of letters and calls system. State agencies at all levels, such as people's congress, political consultative conference and government, set up letters and calls institutions to maintain and increase sound communication and interaction with citizens. As an intermediary agency connecting governments and citizens, letters and calls sectors need to convey citizens' letters and calls to corresponding national institutions. For perfecting letters and calls system of China, these sectors at all levels need to identify function orientation of their own, give the priority to tackle the interest contradiction between citizens and national institutions and decrease bad behaviors (e.g., stopping, seizing-up, blocking-off, intercepting) towards citizens. The staff in letters and calls institutions must elevate their political accomplishments and work efficiency. Laws and regulations should be introduced in succession to manage their words and behaviors and responsibility tracing system also should be constructed.

\subsection{Facilitating Citizen Participation in the Grass-Root NGO}

Among the actors in the policy network, citizens and grass-root NGO have a natural contact. Citizens can join in these organizations possessing the same or similar interest targets as them to enrich their organization resource. Facilitating the movement of citizen participation in the grass-root NGO needs governments' support.

Firstly, governments should make great efforts to support the development of grass-root NGO. As grass-root NGO in China has been in an elementary stage, governments should not only afford imperative policy instructions and financial support, but also strengthen the legislation for grass-root NGO to protect their legitimacy and to stipulate their qualification and authority clearly. Governments must make a quick response to the problems reflected by grass-root NGO and listen to their suggestions and opinions patiently as well. Of great importance is that governments should keep a stable and persistent cooperation relationship with grass-root NGO.

Secondly, governments can not intervene grass-root NGO's independent development. Dahl (1982) indicated that organizations maintaining independence were crucial for democratic development, and that their functions were mainly involved in compelling minimal governments, ensuring political freedom and enhancing public life. Thus it is significant for keeping grass-root NGO's independent development when they interact with governments.

Thirdly, governments should encourage citizens to join in the grass-root NGO. To be specific, governments must boost citizens' organizational awareness and intensify dissemination and instruction so as to make them realize the necessity of organization participation. Fourthly, grass-root NGO also needs to improve themselves. If grass-root NGO would like to attract more citizens to join in, organization articles must be established; organization disciplines must be reinforced; organization members' behaviors must be regulated.

\subsection{Enhancing the Interaction Efficiency between Citizens and Experts/Mass Media}

In the Chinese context, citizens can resort to experts and media to promote public problems enter the government agenda, but there are two preconditions:

1) Guaranteeing relative independence of experts and news media. Ensuring relative independence of experts and scholars requires to focus on deepening political reform of China and to reduce experts who are within the political system. In the public policy process, experts and scholars should not be induced and captured by 
powerful network actors. They should make comments and raise policy approaches objectively and fairly. Before they utilize their professional knowledge and skills to combat problems, these elites need to make field surveys and analyze data obtained in the investigation process. Similar to experts and scholars, news media in China also guarantee the independence of their functions and duties. In modern society, news media mainly contribute their efforts to setting up communication platform for citizens. However, unlike grass-root NGO, there are not natural relation between news media and citizens, which easily leads to an unjust attitude towards a certain matters. It can be seen that news media must keep relative political independence and accept supervision from the outside actively to avert combining power with money to lose impartial standpoint.

2) Improving normativity and reasonability of citizen participation using the Internet. Governments should regulate netizens' words and behaviors, such as guiding netizens to participate in public policy rationally; constructing moral restriction system with regard to citizen participation via Internet; cracking down netizens who work on crime; and etc. With the promotion from experts and news media, citizens can participate in the process of public policy utilizing the Internet in different ways, which can largely improve the efficiency and effectiveness and accelerate policy making course. In the event of Sun Zhigang (Hand, 2006), news media reported this severe incident at first, then three doctors in laws submitted to Standing Committee of NPC to carry out constitutional review on mandatory system. During the period, a wide range of citizens joined in the discussion through the Internet. Eventually, a series of participation behaviors from all the network actors prompted an abolishment of "The Housing Management for Urban Vagrants and Beggars" and a birth of "The Salvage Management to Vagrants and Beggardom in Cities". This typical case could become an important method choice of citizen participation in future.

\section{Conclusion}

This paper mainly studies the problems of citizen participation in the public policy process in the Chinese context based on policy network theory. Through applying the theory about classifications of policy network resources raised by Rhodes to our research, we find that Chinese citizens have no sufficient network resources, especially lack of authority and finance seriously, which can make them in a marginalized position. In the respect of policy belief, Chinese citizens lack rationality and carry with higher utility purpose when participating in the policy process, which also reduces their participation quality. Both network resource occupation and policy belief together constitute the internal factors affecting citizen participation. From the external factors, it can be seen that, compared to other network actors, Chinese citizens locate in the issue network according to the classification of policy network. Besides, in the interaction process with other actors, citizens often suffer isolation and repulsion because they can not fully exchange network resources with every actor in reality. For resolving these difficulties encountered by citizens in China, we put forward some countermeasures and suggestions, such as enriching citizens' policy network resources, strengthening citizens' policy belief, constructing a positive interrelation between citizens and local governments, and etc.

In general, policy network theory provides a new perspective and a valuable direction for researching Chinese citizen participation in the process of public policy. Not only can it excavate deeper reasons of citizens' own, but also display a more comprehensive and dynamic picture concerning interactive relationship among citizens and other network actors. Thus the paper, to a large extent, shrink the gaps existing in previous research. Future studies can analyze typical cases on the basis of this research framework or carry out detailed research to a certain factor.

\section{References}

Arnstein, S. R. (1969). A Ladder of Citizen Participation. Journal of the American Institute of Planners, 35(4), 216-224. http://dx.doi.org/10.1080/01944366908977225

Bingham, L. B., Nabatchi, T., \& O'Leary, R. (2005). The New Governance: Practices and Processes for Stakeholder and Citizen Participation in the Work of Government. Public Administration Review, 65(5), 547-558. http://dx.doi.org/10.1111/j.1540-6210.2005.00482.x

Bo, G. L. (2000). Citizen Participation in Chinese Public Management. Journal of National School of Administration, 5, 27-29.

Chen, X. P. (2012). Government Leading, Limited Market and Citizen Participation in the Local Government's Service Provision: A Case of Public Bike Service in Hangzhou City. Social Sciences Review, 27(3), 38-41.

Chu, S. Y. (2009). An Analysis on the Institutional Environment of Public Participation in China. The Journal of Shanghai Administration Institute, 10(1), 46-55.

Dahl, R. A. (1982). Dilemmas of Pluralist Democracy: Autonomy vs. Control. Yale University Press. 
Deng, F. (2011). An Analysis of Policy Process on Kids of Rural-Labors' Compulsory Education: a Perspective of Policy Network. Modern Education Management, 4, 54-57.

Dye, T. R. (1992). Understanding Public Policy. Englewood Cliffs, NJ: Prentice Hall.

Enserink, B., \& Koppenjan, J. (2007). Public Participation in China: Sustainable Urbanization and Governance. Management of Environmental Quality: An International Journal, 18(4), 459-474. http://dx.doi.org/10.1108/14777830710753848

Fu, G. W., \& Fu, Y. F. (2007). Citizen Participation in Policy Making: Information Channel, Motivation and Frequency. Chinese Public Administration, 12, 92-94.

Gais, T. L., Peterson, M. A., \& Walker, J. L. (1984). Interest Groups, Iron Triangles and Representative Institutions in American National Government. Cambridge University Press.

Hand, K. J. (2006). Using Law for A Righteous Purpose: the Sun Zhigang Incident and Evolving Forms Of Citizen Action in the People's Republic of China. Colum. J. Transnat'l L., 45, 114.

Irvin, R. A., \& Stansbury, J. (2004). Citizen Participation in Decision Making: Is It Worth the Effort?. Public Administration Review, 64(1), 55-65. http://dx.doi.org/10.1111/j.1540-6210.2004.00346.x

Kenis, P. N., \& Schneider, V. (1991). Policy Network and Policy Analysis: Scrutinizing a New Analytical Toolbox. In B. Marin, \& R. Mayntz. (Eds.), Policy Network: Empirical Evidence and Theoretical Considerations. Frankfurt am Main: Campus Verlag.

Kickert, W. J. M., \& Klijn, Koppenjan, J. F. M. (1997). A Management Perspective on Policy Networks. In Kickert W. J. M., Klijn, \& Joop F. M. K. (Eds.), Managing Complex Networks: Strategies for the Public. Sector. London: Sage.

Klijn, E. H., \& Koppenjan, J. F. M. (2000). Public Management and Policy Networks: Foundations of a Network Approach to Governance. Public Management, 2(2), 135-158. http://dx.doi.org/10.1080/146166700411201

Koranteng, R. O., \& Larbi, G. A. (2008). Policy Networks, Politics and Decentralisation Policies in Ghana. Public Administration and Development, 28(3), 212-222. http://dx.doi.org/10.1002/pad.497

Liang, J. L. (2009). Predicament of Chinese Citizens' Participation in Public Policy Making and the Countermeasure. Journal of Sichuan University of Science \& Engineering (Social Sciences Edition), 24(3), 34-36.

Luo, C. P. (2008). Dilemma of Citizen Participation and Solutions. Journal of the Party School of CPC Hangzhou, 2, 59-63.

Marsh, D., \& Rhodes, R. A .W. (1992). Policy Networks in British Government. Clarendon Press. http://dx.doi.org/10.1093/acprof:oso/9780198278528.001.0001

Qi, G. S., \& Wang, L. (2010). Analysis of the Impact of Network Participation on Promoting Public Policy Credibility. Chinese Public Administration, 7, 21-23.

Rhodes, R. A. W. (1990). Policy Networks A British Perspective. Journal of Theoretical Politics, 2(3), 293-317. http://dx.doi.org/10.1177/0951692890002003003

Rhodes, R. A. W. (1992). Beyond Westminster and Whitehall: The Sub-Central Governments of Britain. Taylor \& Francis US.

Rhodes, R. A. W. (1997). Understanding Governance: Policy Networks, Governance, Reflexivity and Accountability. Open University Press.

Roberts, N. (2004). Public Deliberation in an Age of Direct Citizen Participation. The American Review of Public Administration, 34(4), 315-353. http://dx.doi.org/10.1177/0275074004269288

Rong, Z. (2012). The Model of Multi-sources for Public Decision-making in Grass-roots Units and its Characteristics. Academic Journal of Jinyang, 3, 35-42.

Sabatier, P. A. (1988). An Advocacy Coalition Framework of Policy Change and the Role of Policy-Oriented Learning therein. Policy Sciences, 21(3), 129-168. http://dx.doi.org/10.1007/BF00136406

Sun, Y. Y. (2006). Ten Dilemmas about Chinese Citizen Participation in the Public Policy Process. Chinese Public Administration, 1, 43-45.

Tang, H. F. (2004). Policy Networks and Policy Outcomes in China: Changes of Interest Allocation in the Countryside Reform of Tax and Fee. Journal of Zhejiang Province Party Committee School, 1, 31-36. 
Wang, L. Z. (2005). Research on Citizen Participation in the Public Policy Process in China during Transitional Period: Based on Interest Perspective. Chinese Public Administration, 8, 86-88.

Wang, Y. H. (2011) Citizen Participation System in the Perspective of Public Policy Making: A Case of the Open Government Decision Making in Hangzhou City. Journal of Public Management, 8(3), 24-32.

Webler, T., \& Renn, O. (1995). A Brief Primer on Participation: Philosophy and Practice. Fairness and Competence in Citizen Participation, 10, 17-33. http://dx.doi.org/10.1007/978-94-011-0131-8_2

Wei, N., \& Yuan, B. (2009). Citizen Participation in Urban Public Policy Making under the Environment of Network. Chinese Public Administration, 3, 82-85.

Yin, Y. H., \& Shang, H. P. (2009). Breakthrough of Citizen Participation in Order: A Perspective of Structural Changes in Letters and Calls Organizations. Chinese Public Administration, 10, 81-84.

Zang, Y. Z., \& Wang, X. B. (2012). Problems and Countermeasures of Chinese Citizen Participation Public Decision-Making. Journal of Chongqing University of Science and Technology (Social Sciences Edition), 5, 61-63.

Zheng, H., De, J. M., \& Koppenjan, J. (2010). Applying Policy Network Theory to Policy-Making in China: the Case of Urban Health Insurance Reform. Public Administration, 88(2), 398-417. http://dx.doi.org/10.1111/j.1467-9299.2010.01822.x

Zheng, P., \& Xue, B. (2009). The Mechanism of Public Opinion Formation in Internet and its Approach to Influence the Policy-Making. Chinese Public Administration, 1, 61-65.

Zhu, C. K. (2011). Policy Network and Policy Tool: Theoretical Foundation and Chinese Implementation. Fudan University Press.

Zhu, S. M. (2007). Citizen Participation in Livelihood Decision-Making: New Techniques and Strategies for Rural Governance. Journal of Public Management, 4(3), 110-116.

\section{Copyrights}

Copyright for this article is retained by the author(s), with first publication rights granted to the journal.

This is an open-access article distributed under the terms and conditions of the Creative Commons Attribution license (http://creativecommons.org/licenses/by/3.0/). 